\title{
PENGUJIAN EFFISIENSI TRANSFORMATOR INTI FERRIT DI LABORATORIUM TEKNIK ELEKTRO UNIVERSITAS PGRI PALEMBANG
}

\author{
Emidiana $^{1)}$, Febriyanto Saputra ${ }^{2)}$ \\ ${ }^{1), 2)}$ Teknik Elektro Universitas Palembang \\ e-mail : emidiana@univpgri-palembang.ac.id
}

\begin{abstract}
Abstrak--Transformator merupakan alat listrik elektromagnetik statis yang berfungsi memindahkan dan mengubah daya listrik dari suatu rangkaian listrik ke rangkaian listrik lainnya dengan prinsip induksi elektromagnetis. Transformator digunakan secara luas, baik dibidang tenaga listrik maupun elektronika, dengan bermacam-macam klasifikasi, salah satunya dari sisi inti transformatornya. Pada penelitian ini akan dibahas tentang effisiensi transformator inti ferrit yang dibandingkan dengan transformator inti besi, jika digunakan pada tenaga listrik. Penelitian ini yang dilakukan di laboratorium Teknik Elektro Universitas PGRI Palembang. Dari hasil pengukuran didapat bahwa effisiensi transformator inti ferrit lebih rendah jika dibandingkan dengan transformator inti besi dan tidak layak jika digunakan pada tenaga listrik.
\end{abstract}

Kata kunci : trafo inti ferrit, transformator inti besi, effisiensi

\begin{abstract}
The transformer is a static electromagnetic device that functions to transfer the electrical power of an electrical circuit to another electrical circuit with the principle of electromagnetic induction. The transformer is widely used, both in the field of electricity and electronics. In this study we will discuss the efficiency of ferrite core transformers compared to iron core transformers, if used in electric power. This research was located at the Electrical Engineering laboratory Universitas PGRI Palembang. From the measurement results concluded that the ferrite core transformer efficiency is lower when compared to iron core transformers and not feasible if used in electric power.
\end{abstract}

Keywords: ferrite core transformer, iron core transformer, efficiency

\section{PENDAHULUAN}

Transformator digunakan secara luas, baik dibidang tenaga listrik maupun elektronika. Dalam sistem tenaga, tegangan transformator dapat dipilih yang sesuai dan ekonomis untuk tiap-tiap kebutuhan, misalnya kebutuhan akan tegangan tinggi dalam pengiriman daya listrik jarak jauh. Dibidang elektronika, transformator digunakan sebagai gandengan impedansi antara sumber dan beban, untuk memisahkan satu rangkaian dari rangkaian lain, dan untuk menghambat arus searah sambil tetap melakukan arus bolak-balik antara rangkaian.[3]

Pembahasan pada penelitian ini dibatasi pada rancang bangun trafo inti besi dan inti ferrit, pengukuran arus pada masing-masing trafo yang bertujuan untuk mendapatkan nilai effisiensi dari kedua jenis transformator dan membandingkan effisiensi dari kedua trafo tersebut. 


\section{TINJAUAN PUSTAKA}

Transformator merupakan alat listrik elektromagnetik statis yang berfungsi memindahkan dan mengubah daya listrik dari suatu rangkaian listrik ke rangkaian listrik lainnya, dengan frekuensi yang sama dan perbandingan tertentu melalui suatu gandengan magnet dengan prinsip induksi elektromagnetis, dimana jumlah lilitannya berbanding lurus dengan perbandingan tegangannya tetapi berbanding terbalik dengan perbandingan arusnya[5].

Penggunaan trafo dalam system tenaga memungkinkan dipilihnya tegangan yang sesuai dan ekonomis untuk macam-macam kebutuhan, misalnya : kebutuhan teganan tinggi dan kebutuhan pengiriman jarak jauh. Dibidang elektronika, trafo digunakan sebagai gandengan impedansi antara sumber dan beban, pemisah antar rangkaian dan penghambar arus searah sambil tetap melalukan arus bolak balik [1]

\section{Prinsip Kerja Transformator}

Transformator terdiri dari dua kumparan yaitu primer dan sekunder yang bersifat induktif. Kedua kumparan tersebut terpisah secara elektris tetapi terhubung secara magnetis melalui jalur yang memiliki reluktansi (reluctance) rendah. Jika kumparan primer dihubungkan dengan sumber tegangan bolak-balik maka fluks bolak-balik akan muncul di dalam inti yang dilaminasi, karena kumparan tersebut membentuk jaringan tertutup maka mengalirlah arus primer. Karena adanya fluks pada kumparan primer maka terjadi induksi (self induction) dan terjadi juga induksi di kumparan sekunder karena pengaruh induksi dari kumparan primer tersebut atau disebut sebagai induksi bersama (mutual induction) yang menyebabkan timbulnya fluks magnet di kumparan sekunder, sehingga di rangkaian sekunder akan mengalir arus jika di bebani, dan energi listrik dapat ditransfer secara keseluruhan (secara magnetisasi) [5]

\section{Macam-macam Transformator Berdasarkan Intinya}

\section{Transformator Inti Ferrit}

Intinya terbuat dari campuran zinc, besi, mangan dan beberapa bahan lain. Banyak digunakan sebagai power supply jenis switching. Dengan bekerja pada frekuensi tinggi, transformator ini memiliki ukuran lebih kecil dari transformator frekuensi rendah. Akan tetapi, transformator ini di pasaran hanya tersedia secara terbatas untuk spesifikasi tertentu, sehingga transformator biasanya didesain dan dibuat sendiri untuk aplikasi tertentu [2]

\section{Trafo Inti Udara}


Terdiri dari 2 lilitan tanpa inti, digunakan untuk tujuan tertentu dengan pemakaian tegangan rendah. Umumnya tidak memerlukan daya yang besar dan effisiensinya sangat rendah 3. Trafo Inti Besi

Trafo jenis ini merupakan trafo yang paling banyak digunakan . Material inti besinya dibuat berupa lembaran-lembaran yang bertujuan untuk meningkatkan effisiensinya.

\section{Kumparan Transformator}

Garis tengah atau tebal kumparan (kawat tembaga) menentukan kemampuannya saat dilalui arus listrik. Bila arus listrik yang mengalir melebihi kemampuan kawat, akan menyebabkan kawat menjadi panas dan jika arus yang melalui kawat jauh melebihi kemampuan kawat, kawat akan terbakar dan putus.

Tabel 1. Diameter kawat

\begin{tabular}{|c|c|}
\hline Diameterkawat $(\mathrm{mm})$ & Kemampuan dilalui arus ( A ) \\
\hline 0,1 & $0,016-0,024$ \\
\hline 0,15 & $0,035-0,053$ \\
\hline 0,2 & $0,063-0,094$ \\
\hline 0,25 & $0,098-0,147$ \\
\hline 0,3 & $0,141-0,212$ \\
\hline 0,35 & $0,190-0,289$ \\
\hline 0,4 & $0,251-0,377$ \\
\hline 0,45 & $0,318-0,477$ \\
\hline 0,5 & $0,390-0,588$ \\
\hline 0,6 & $0,566-0,849$ \\
\hline 0,7 & $0,770-1,16$ \\
\hline 0,8 & $1,01-1,51$ \\
\hline 0,9 & $1,27-1,91$ \\
\hline 1 & $1,57-2,36$ \\
\hline 1,5 & $3,53-5,3$ \\
\hline 2 & $6,28-9,42$ \\
\hline 2,5 & $9,82-14,73$ \\
\hline 3 & $14,14-21,20$ \\
\hline 3,5 & $19,24-28,86$ \\
\hline 4 & $25,14-37,71$ \\
\hline
\end{tabular}

Kawat pada inti trafo dipasang dengan cara melilitkan kawat secara merata, antara satu dengan yang lainnya diberi isolasi kertas tipis. Pembuatan cabang dari lilitan dilakukan dengan membengkokkan kawat diluar lilitan, untuk kemudian dilanjutkan manggulung lagi kawat sampai selesai. Untuk melakukan hal tersebut, pada lobang tempat gulungan dimasukkan sepotong kayu dengan ukuran yang sesuai yang pada kedua belah ujung intinya dimasukkan as dari logam yang berhubungan dengan alat pemutar. 


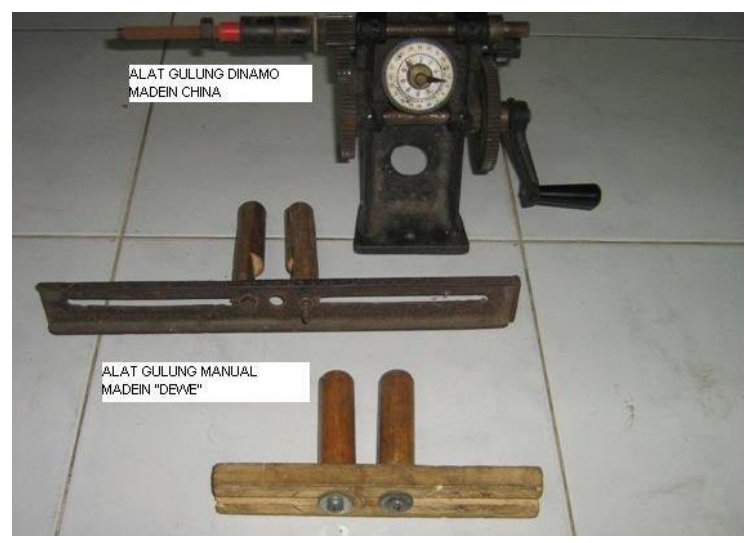

Gambar 1. Alat Gulung Transformator [8]

\section{Rugi-rugi dan Effisiensi [2]}

Effisiensi trafo adalah perbandingan antara daya keluar dan daya masuk. Trafo ideal adalah trafo yang memiliki effisiensi $100 \%$, yaitu trafo yang tidak memiliki kehilangan daya sama sekali. Tetapi pada kenyataannya tidak ada trafo yang ideal, karena pasti ada daya yang hilang atau rugi - rugi pada trafo tersebut.

Effisiensi $(\eta)=\frac{\text { daya } \text { keluar }}{\text { daya } \text { masuk }}=\frac{\text { daya } \text { keluar }}{\text { daya } \text { keluar }+\sum \text { rugi }}=1-\frac{\sum \text { rugi }}{\text { daya } \text { masuk }}$

Rugi-rugi pada transformator terbagi atas :

1. Rugi Tembaga $\left(\mathrm{P}_{\mathrm{cu}}\right)$

Rugi - rugi yang disebabkan arus beban yang mengalir pada kawat tembaga. Karena arus yang mengalir berubah-ubah, maka rugi tembaga juga berubah berdasarkan beban.

$$
\mathrm{P}_{\mathrm{cu}}=\mathrm{I}^{2} \mathrm{R}
$$

\section{Rugi Besi (Pi)}

Terdiri dari :

- Rugi histeresis, rugi-rugi yang disebabkan oleh fluks bolak-balik pada inti besi

$$
\begin{aligned}
& \mathrm{P}_{\mathrm{h}}=\mathrm{K}_{\mathrm{hf}} B_{\text {max }}^{1,6} \text { watt } \\
& \mathrm{K}_{\mathrm{h}}=\text { konstanta } \\
& \mathrm{B}_{\max }=\text { fluks maksimum (Weber) }
\end{aligned}
$$

- Rugi arus Eddy, rugi-rugi yang disebabkan arus pusar pada inti besi

$$
\mathrm{P}_{\mathrm{e}}=K_{e}^{2} \mathrm{f}^{2}
$$

Jadi rugi besi $\left(\mathrm{P}_{\mathrm{i}}\right)=\mathrm{P}_{\mathrm{h}}+\mathrm{P}_{\mathrm{e}}$ 


\section{TRANSFORMATOR KHUSUS [4]}

\section{Ototransformator}

Ototransformator merupakan merupakan transformator yang terdiri dari satu kumparan, yang dihubungkan sedemikian rupa sehingga sisi primer dan sisi sekunder memiliki secara bersama sebagian kumparan. Atau dapat dikatakan ototransformator merupakan satu kumparan yang dicabangkan

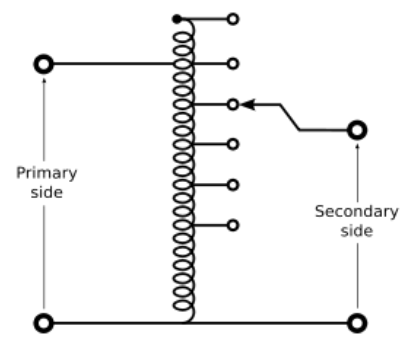

Gambar 2. Ototransformator [6]

2. Transformator Penyearah

Untuk mendapatkan arus searah untuk bermacam-macam keperluan, digunakan penyearah. Untuk menghubungkan penyearah ke jaringan, diperlukan sebuah trafo khusus

3. Transformator Ukur

Tegangan kerja pada instalasi listrik seperti pusat pembangkit dan gardu induk umumnya tegangan tinggi dan arus yang mengalir adalah arus yang besar pula. Alat ukurnya menjadi sangat mahal, jika besaran-besaran tersebut diukur secara langsung. Karena itu dibuat transformator khusus untuk menurunkan tegangan atau arus yang besar tersebut.pada rasio tertentu. Transformator khusus tersebut dinamakan transformator ukur, yang terdiri dari 2 jenis, yaitu trafo arus dan trafo tegangan

4. Transformator Uji Tegangan Tinggi

Trafo uji tegangan tinggi dibuat dalam hubungan hemat, yaitu sebagai ototransformator, dengan konstruksi secara bersusun atau kaskade

5. Reaktor

Sistem tenaga listrik sering menggunakan kumparan sebagai induktor atau reaktor yang dihubung seri untuk membatasi besar arus hubung singkat yang dapat terjadi saat gangguan

6. Magnet dan Transformator Superkonduktif

Transformator yang memanfaatkan sifat superkonduktivitas

7. Transformator Khusus Lain 
Merupakan transformator yang memiliki desain khusus yang disesuaikan dengan penggunaan. Contohnya : transformator mini, transformator tambang, transformator las, transformator dengan tegangan yang rendah

\section{METODE PENELITIAN}

Penelitian dilaksanakan di Laboratorium Teknik Elektro Universitas PGRI Palembang

\section{Perancangan dan Perhitungan}

1. Menentukan Luas Inti Trafo

Luas inti trafo $(\mathrm{A})=0,98 \sqrt{P}$

Luas trafo inti ferrit $=$ luas trafo inti besi

2. Menentukan jumlah lilitan per volt

Jumlah lilitan per volt $=\frac{f}{A}$

3. Menentukan diameter kawat tembaga

Diameter kawat ditentukan dengan melihat tabel 1, berdasarkan arus yang akan mengalir pada kawat tembaga tersebut

4. Menghitung effisiensi trafo inti besi dan inti ferrit

$\eta=\frac{\text { daya } \text { keluar }}{\text { daya } \text { masuk }} \times 100 \%$

\section{HASIL DAN ANALISA}

Luas trafo inti ferrit $=$ luas trafo inti besi $=5 \mathrm{~cm}^{2}$

Lilitan per volt $=\frac{f}{A}=\frac{50}{5}=10$

$\mathrm{A}=0,98 \sqrt{P}$

$\mathrm{P}=\left(\frac{A}{0,98}\right)^{2}=25 \mathrm{~W}$

$\mathrm{V}$ pada sisi primer 220, maka $\mathrm{I}=\frac{25}{220}=0,11 \mathrm{~A} \quad$ diameter kawat yang sesuai $0,25 \mathrm{~mm}^{2}$

$\mathrm{V}$ pada sisi sekunder $6 \mathrm{~V}$, maka $\mathrm{I}=\frac{25}{6}=4,17 \mathrm{~A} \quad$ diameter kawat yang sesuai $1,5 \mathrm{~mm}^{2}$

Jumlah lilitan pada sisi primer $=10 \times 220=2200$ lilitan

Jumlah lilitan pada sisi sekunder $=10$ × $6=60$ lilitan

Diameter kawat sisi primer $0,25 \mathrm{~mm}$, sedangkan pada sisi sekunder $1,5 \mathrm{~mm}$ 


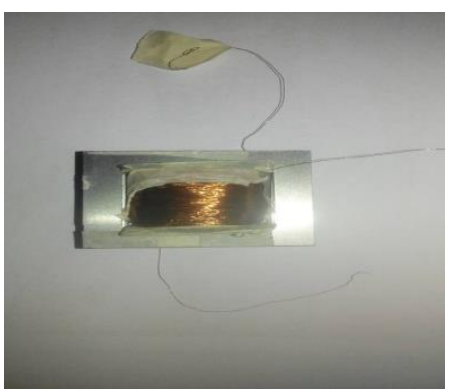

Gambar 3. Trafo Inti Besi

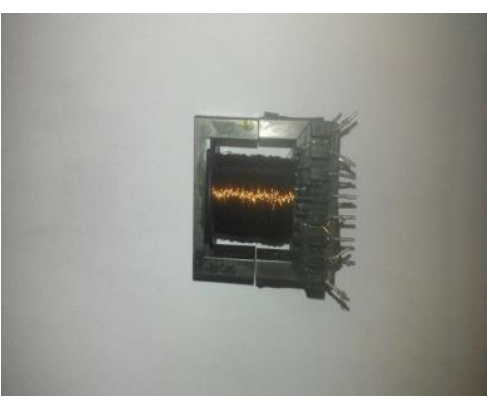

Gambar 4. Trafo Inti Ferrit

\section{PENGUKURAN}

A.Transformator inti ferit

\begin{tabular}{|l|l|l|l|}
\hline No & $V_{\text {in }}($ Volt $)$ & $V_{\text {out }}($ Volt $)$ & $I_{\text {out }}(\mathrm{mA})$ \\
\hline 1 & 48 & 8 & 8,2 \\
\hline 2 & 48 & 8,5 & 8,3 \\
\hline 3 & 49 & 8,5 & 8,3 \\
\hline 4 & 48 & 8 & 8,2 \\
\hline 5 & 48 & 8 & 8,2 \\
\hline
\end{tabular}

B.Transformator inti besi

\begin{tabular}{|l|l|l|l|}
\hline No & $V_{\text {in }}$ Volt $)$ & $V_{\text {out }}$ Volt $)$ & $I_{\text {out }}(\mathrm{mA})$ \\
\hline 1 & 60 & 29 & 0,026 \\
\hline 2 & 60 & 30 & 0,025 \\
\hline 3 & 61 & 30 & 0,026 \\
\hline 4 & 62 & 30 & 0,025 \\
\hline 5 & 60 & 29 & 0,026 \\
\hline
\end{tabular}

\section{Efisiensi transformator inti besi}

$$
\begin{aligned}
& I_{\text {out rata rata }}=I_{2 \text { rata rata }}=\frac{0,026+0,025+0,026+0,025+0,026}{5}=0,0256 \mathrm{~mA} \\
& \mathrm{I}_{1}=\frac{\mathrm{N}_{2} \cdot \mathrm{I}_{2}}{\mathrm{~N}_{1}}=\frac{440(0,0256)}{880} \mathrm{I}_{1}=0,0128 \mathrm{~mA} \\
& V_{\text {in rata-rata }}=V_{1 \text { rata-rata }}=\frac{60+60+61+62+60}{5}=60,6 \mathrm{~V} \\
& \mathrm{P}_{1}=V_{1} \cdot I_{1}=(60,6) \cdot(0,0000128)=0,00077568 \mathrm{~W} \\
& V_{\text {out }} \text { rata rata }=\frac{29+30+30+30+29}{5}=29,6 \mathrm{~V} \\
& \mathrm{P}_{2}=V_{2} \cdot I_{2}=(29,6) \cdot(0,0000256)=0,000075776 \\
& \eta=\frac{\mathrm{P}_{2}}{\mathrm{P}_{1}} \times 100 \%=\frac{0,000075776}{0,000077568} \times 100 \%=97,68 \%
\end{aligned}
$$




\section{Effisiensi transformator inti ferit}

$$
\begin{aligned}
& I_{\text {out rata rata }}=I_{2 \text { rata rata }}=\frac{8,2+8,3+8,3+8,2+8,2}{5}=8,24 \mathrm{~mA} \\
& \mathrm{I}_{\mathrm{I}}=\frac{\mathrm{N}_{2} \cdot \mathrm{I}_{2}}{\mathrm{~N}_{1}}=\frac{440(8,24)}{880}=4,12 \mathrm{~mA} \\
& V_{\text {in }}=\frac{48+48+49+48+48}{5}=48.2 \\
& \mathrm{P}_{\mathrm{I}}=\mathrm{V}_{\mathrm{I}} \cdot \mathrm{I}_{\mathrm{I}}=(48,2)(0,00412) \mathrm{W}=0,198584 \mathrm{Watt} \\
& \mathrm{V}_{\text {out }}=\frac{8,2+8,3+8,3+8,2+8,2}{5}=8,2 \\
& \mathrm{P}_{2}=\mathrm{V}_{2} \cdot \mathrm{I}_{2}=(8,2)(0,00824) \mathrm{W}=0,067568 \text { Watt } \\
& \eta=\frac{\mathrm{P}_{2}}{\mathrm{P}_{1}} \times 100 \%=\frac{0,067568}{0,198584} \times 100 \%=34,02 \%
\end{aligned}
$$

\section{KESIMPULAN}

1. Dari hasil perhitungan didapat, kawat yang harus dipakai pada sisi primer berdiameter 0,25 $\mathrm{mm}^{2}$ dan sisi sekunder berdiameter $1,5 \mathrm{~mm}^{2}$.

2. Jumlah lilitan pada sisi primer sebanyak 2200 lilitan dan pada sisi sekunder 60 lilitan

3. Transformator inti ferit memiliki efisiensi $34,02 \%$

4. Transformator inti besi memiliki efisiensi $97,68 \%$

5. Transformator inti ferit tidak dapat digunakan sebagai transformator daya karena effisiensinya yang rendah

\section{DAFTAR PUSTAKA}

1. Zuhal, "Dasar Teknik Tenaga Listrik dan Elektronika Daya", PT Gramedia Pustaka Utama, Jakarta, 2000

2. N. Mohan, T. M. Undeland, and W. P. Robbins, Eds., Power Electronics : Converters, Applications, and Design, 3rd ed. Minnesota: Wiley, 2003.

3. Zuhal, Dasar Tenaga Listrik, Penerbit ITB Bandung, 1991

4. Abdul Kadir, Transformator, Penerbit Universitas Indonesia, 2010

5. 5.http://repository.usu.ac.id/bitstream/handle/123456789/20976/Chapter\%20II.pdf;jsessioni $\mathrm{d}=\mathrm{C} 7 \mathrm{E} 16391 \mathrm{BE} 153556 \mathrm{~A} 6712 \mathrm{~B} 6 \mathrm{~F} 8 \mathrm{CB} 21 \mathrm{E} 47$ ?sequence $=3$

6. https://en.wikipedia.org/wiki/Autotransformer

7. https://goodarif.files.wordpress.com/2013/01/gel-pe.jpg

8. http://hobbytehkniselektronika.blogspot.com/2011/09/alat-untuk-mengulung-dinamo-dan$\underline{\text { trafo.html }}$ 
JURNAL AMPERE

Volume 3 No 2, Desember 2018

P-ISSN : 2477-2755

E-ISSN : 2622-2981 